
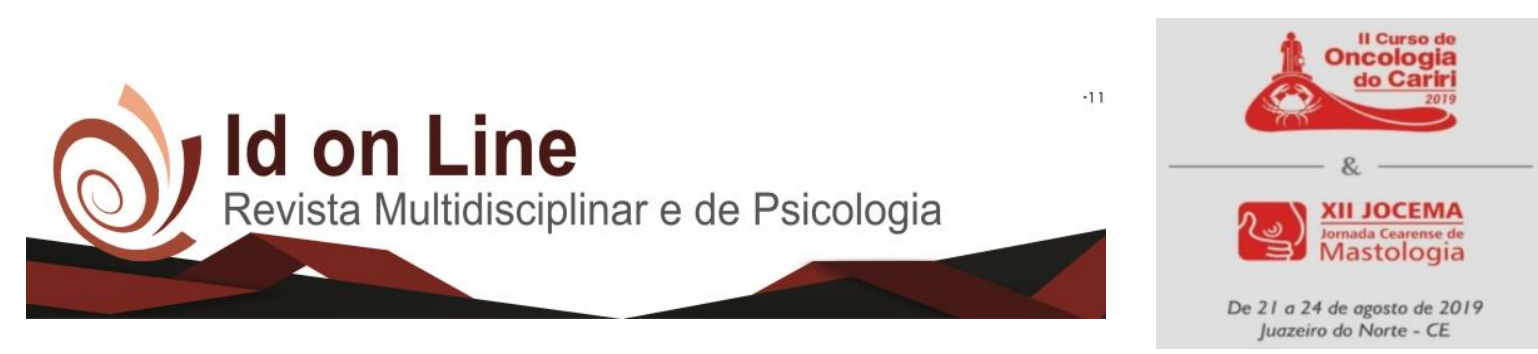

DOI: 10.14295/idonline.v13i46.2003

Resumo

\title{
EDUCAÇÃO EM SAÚDE COMO INSTRUMENTO NA PREVENÇÃO DO CÂNCER DE COLO UTERINO
}

\author{
Maria Andrezza Gomes Maia' , Jacyanne Vieira Gino ${ }^{1}$, Patrícia Maria de Albuquerque Brayner².
}

Introdução: $O$ câncer de colo uterino é o terceiro tipo mais comum de câncer nas mulheres no Brasil, superado apenas pelo câncer de mama e câncer de cólon e reto. O exame de Papanicolau é o método principal e mais utilizado para o seu rastreio desse tipo de câncer. Entretanto, a adesão ao exame ainda está distante da cobertura preconizada pelo Ministério da Saúde, que é de 80 a $85 \%$ das mulheres na faixa etária de 25 a 64 anos. Tal situação pode ocorrer pela existência de medos, tabus, desconhecimento acerca da doença, além de condições socioeconômicas e culturais. Nesse cenário, as ações de educação em saúde surgem como uma forma de auxiliar na adesão das mulheres ao exame Papanicolau, uma vez que possibilitam às mulheres o esclarecimento de dúvidas acerca do exame e da doença. Objetivo: Relatar uma experiência de educação em saúde na prevenção do câncer de colo uterino na região do Cariri Cearense. Método: Foi realizada uma roda de conversa na UBS do Sítio Lagoa, em Barbalha-CE, no dia 27 de maio de 2019, juntamente com outras atividades comemorativas ao Dia das Mães. Durante a conversa foi abordada a importância da realização do exame Papanicolau para detecção precoce do câncer do colo uterino e discorreu-se sobre as causas e o prognóstico desse tipo de câncer. Além disso, as mulheres puderam tirar suas dúvidas sobre o exame e tinham a opção de realizá-lo após a conversa. Resultado: A ação contou com 50 participantes com idade entre 18 e 65 anos. No início, o público apresentou-se pouco apto a participar das discussões. Contudo, com o decorrer da conversa, as mulheres se tornaram mais participativas, relatando seus medos, que variaram do constrangimento durante o exame à falta de informação sobre sua importância. Percebeu-se que ao se abordar a temática do câncer de colo uterino, principalmente a infecção sexual pelo HPV como uma de suas principais causas, as mulheres demonstraram desconhecimento sobre o assunto e interesse em discuti-lo mais. Como resultado, das 50 mulheres que participaram da roda de conversa, 28 realizaram o exame Papanicolau após a atividade. Conclusão: As ações de educação em saúde revelam-se como uma estratégia eficaz na transmissão de informações à população, contribuindo para promoção à saúde e prevenção de doenças, como no caso do câncer de colo uterino. Além disso, percebeu-se a necessidade de mais ações desse tipo, abordando outros temas relacionados à saúde.

Palavras-chave: neoplasias, colo uterino, educação em saúde.

\footnotetext{
${ }^{1}$ Discente do curso de medicina da Universidade Federal do Cariri

2 Docente do curso de medicina da Universidade Federal do Cariri
} 


\section{Referências}

BRITO-SILVA, Keila et al. Integralidade no cuidado ao câncer do colo do útero: avaliação do acesso. Revista de Saúde Pública, [s.1.], v. 48, n. 2, p.240-248, abr. 2014. FapUNIFESP (SciELO).

FERNANDES, J. V. et al. Conhecimentos, atitudes e prática do exame de Papanicolaou por mulheres no Nordeste do Brasil. Rev.Saúde Pública, São Paulo, v.43, n.5, p. 851-8, 2009.

FERREIRA, M. L. da S. M. Motivos que influenciam a não-realização do exame dePapanicolaou segundo a percepção de mulheres. Esc. Anna Nery Rev. Enfermagem, Rio de Janeiro, v. 13 n. 2, p. 378-384, 2009.

INSTITUTO NACIONAL DE CÂNCER (Brasil). Estimativa 2010. Incidência do Câncer no Brasil. Rio de Janeiro: INCA, 2009.

SALCI, Maria Aparecida et al. Educação Em Saúde E Suas Perspectivas Teóricas: Algumas Reflexões. Texto \& Contexto- Enfermagem, Florianópolis, v. 1, n. 22, p.224-230, 10 jul. 2012. 